\title{
Prevalence of Conjunctivitis in Low Developing Countries: The Case in University Teaching Hospital of Kara in Togo
}

\author{
Kokou Messan Amedome ${ }^{1}$, Codjo Rodrigue Assavedo ${ }^{2 *}$, Chakiratou \\ Abouki $^{3}$, Koffi Didier ${ }^{4}$ and Komi Balo ${ }^{5}$ \\ ${ }^{1}$ University Teaching Hospital of Kara, Togo \\ ${ }^{2}$ Ophthalmology Teaching and Research Unit, Department of Surgery and Surgical \\ Specialties, Faculty of Medicine, University of Parakou, Benin \\ ${ }^{3}$ University Teaching Hospital of Kutuku, Hubert Maga of Cotonou, Benin \\ ${ }^{4}$ Bè Hospital, Lomé, Togo \\ ${ }^{5}$ Sylvanus Olympio University Teaching Hospital of Lomé, Togo \\ *Corresponding Author: Codjo Rodrigue Assavedo, Ophthalmology Teaching and \\ Research Unit, Department of Surgery and Surgical Specialties, Faculty of Medicine, \\ University of Parakou, Benin.
}

Received: November 18, 2021

Published: December 14, 2021

(C) All rights are reserved by Kokou Messan

Amedome., et al.

\begin{abstract}
Introduction: Conjunctivitis is an inflammation of the conjunctival mucosa regardless of the cause. It is the most common cause of "red eye". The aim of this study was to determine the prevalence of conjunctivitis at Kara University Teaching Hospital.

Methods: We carried out a retrospective and descriptive study on the files of patients who consulted in the ophthalmology department of the Kara University Teaching Hospital

and whose diagnosis of conjunctivitis was retained over the period from January 1, 2017 to December 31, 2019, i.e. a period 03 years old.

Results: Our target population was 550 patients from which we had collected a total of 248 cases of conjunctivitis, i.e. a hospital prevalence of $45.09 \%$. The average age of the respondents was 30.20 years with extremes of 6 months and 78 years. The median was 26.50 years. The age group [0-40] years was the most represented. There was a female predominance with an F/M ratio of 1.53 . Pupils, students (34.90\%) and civil servants (22.30\%) were the most affected. Pain, pruritus, visual impairment, and eye redness were the most frequent reasons for consultation.

Conclusion: Conjunctivitis is a frequent condition in our community and it uses statistical and epidemiological data to better equip itself in the fight against this pathology.
\end{abstract}

Keywords: Prevalence; Conjunctivitis; Kara

\section{Introduction}

Conjunctivitis is an inflammation of the conjunctival lining regardless of the cause [1]. It is the most common cause of "red eyes" [2]. Cosmopolitan, conjunctivitis affects all age groups in all populations [3]. In general and specialized medical consultations, it is by far the most frequent ocular condition where it accounted for 25 to $55 \%$ of all causes of ophthalmological consultations. They represent $5 \%$ of consultations at the Institute of Tropical Ophthalmology of Africa [4,5]. Thus, the ophthalmologist working in a tropical environment is daily confronted with the problem of conjunctivitis, the infectious aetiologies of which, in particular bacterial and viral, are the most frequent.

Citation: Kokou Messan Amedome., et al. "Prevalence of Conjunctivitis in Low Developing Countries: The Case in University Teaching Hospital of Kara in Togo". Acta Scientific Ophthalmology 5.1 (2022): 21-26. 
These conjunctivitis, which are often not serious, can, due to a lack of diagnosis and treatment, develop into complications. Neglected conjunctivitis can progress to inflammation of the cornea which is likely to puncture, with a risk of the infection spreading inside the eyeball and to the nervous system. If conjunctivitis is generally confined to the eye, it is however responsible for significant morbidity. The prevalence of conjunctivitis in the entire population of the Inner Niger Delta was 2\% [6]. A similar study carried out by Niébé in the ophthalmology department of the Yalgado Ouédraogo National Hospital Center noted the prevalence of conjunctivitis at $25 \%$ [7]. In Togo, according to a survey carried out by Ayéna in 2012 in the Kozah region, neonatal conjunctivitis alone represented 8\% [8]. However, no study on the prevalence of conjunctivitis in general has yet been carried out in the Togolese population. It therefore seemed appropriate to initiate this study, the aim of which was to determine the hospital frequency of conjunctivitis.

\section{Materials and Methods}

This was a descriptive cross-sectional retrospective study of the records of patients who consulted in the ophthalmology department of University Teaching Hospital Kara over the period from January 1, 2017 to December 31, 2019, i.e. a period of 03 years. We included in our study a random sampling of 550 files of patients who consulted in the ophthalmology department of the University Teaching Hospital of Kara over the period from January 1, 2017 to December 31, 2019 and whose diagnosis of conjunctivitis was retained, i.e. 248. The parameters studied were represented by sociodemographic and clinical data. The analysis and processing of the data collected was done by EPI INFO software, Microsoft Word and Excel 2019, SPSS (Statistical Package for the Social Sciences).

Comparisons between groups were assessed using the chisquare test for qualitative variables and t-test for quantitative variables with the p-value at the $5 \%$ threshold.

\section{Results}

\section{Sample size}

During this study period from January 01, 2017 to December 31, 2020 (03 years), 248 of the 550 patient files who consulted in the ophthalmology department of University Teaching Hospital of Kara were selected for the study.

\section{Hospital frequency of conjunctivitis}

The hospital frequency of conjunctivitis was $45.09 \%$. We have reported in Table I the distribution of patients according to ophthalmological conditions.

\begin{tabular}{|l|c|c|}
\hline & Size & Percentage (\%) \\
\hline Ametropia & 155 & 28.18 \\
\hline Conjunctivitis & 248 & 45.09 \\
\hline Episcleritis & 3 & 0.55 \\
\hline Chalazion & 3 & 0.55 \\
\hline Others & 302 & 54.91 \\
\hline Total & 550 & 100.00 \\
\hline
\end{tabular}

Table 1: Frequency of the different ophthalmological conditions.

Socio-demographic and epidemiological data

Age distribution

The average age of the respondents was 30.20 years with extremes of 6 months and 78 years. The median was 26.50 years. The distribution of respondents according to age groups is shown in table 2.

\begin{tabular}{|l|c|c|}
\hline & Size & Percentage \% \\
\hline$[6 \mathrm{M}-1]$ & 8 & 3.20 \\
\hline$[1-10]$ & 32 & 12.90 \\
\hline$[10-20]$ & 49 & 19.80 \\
\hline$[20-30]$ & 44 & 17.70 \\
\hline$[30-40]$ & 38 & 15.30 \\
\hline Over 40 & 77 & 31.00 \\
\hline Total & 248 & 100.00 \\
\hline
\end{tabular}

Table 2: Distribution by age group.

$$
\mathrm{M}=\text { month. }
$$

The age groups of 10-19 years and 40 years and over were predominant with $19.80 \%$ and $31 \%$ respectively.

\section{Gender}

There were 150 female subjects and 98 male subjects, i.e. a sex ratio M/F: 0.65 . The distribution of respondents by sex is shown in figure 1.
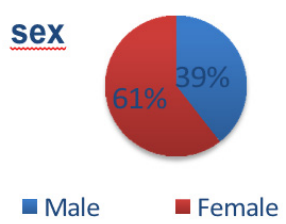

Figure 1: Distribution diagram by sex. 


\section{Profession}

We have reported in table 3 the distribution of patients by profession.

\begin{tabular}{|l|c|c|}
\hline & Size & Percentage \% \\
\hline Officials & 55 & 22.17 \\
\hline Housewife & 23 & 9.27 \\
\hline Trader & 13 & 5.24 \\
\hline Farmer & 5 & 2.01 \\
\hline Workers & 19 & 7.66 \\
\hline Pupil/Student & 86 & 34.70 \\
\hline Unemployed & 17 & 6.85 \\
\hline Not precised & 30 & 12.10 \\
\hline Total & 248 & 100.00 \\
\hline
\end{tabular}

Table 3: Distribution of patients by profession.

The subjects with conjunctivitis surveyed were represented by the group of pupils/students, i.e. a percentage of $34.80 \%$, followed by civil servants (22.30\%) and housewives (9.30\%). Manual workers and others accounted for $7.70 \%$ and $9.30 \%$. Cultivators accounted for $2.00 \%$.

\section{Symptoms}

We have reported in table 4 the distribution according to the reasons for consultation.

\begin{tabular}{|l|c|c|}
\hline & Size & Percentage \% \\
\hline Ocular pain & 99 & 39.92 \\
\hline Icthing & 92 & 37.01 \\
\hline Tearing & 25 & 10.08 \\
\hline Blurred vision & 58 & 23.39 \\
\hline Ocular Redness & 42 & 16.94 \\
\hline Tingling & 30 & 12.01 \\
\hline Ocular Trauma & 9 & 3.63 \\
\hline
\end{tabular}

Table 4: Distribution of patients according to the reasons for consultation.

Eye pain and eye pruritus were found in 39.92\% and $37.01 \%$ of cases, respectively. We noted visual blurring and eye redness in 23.39 and $16.94 \%$ of patients. The feeling of grain of sand (tingling) and tearing represented $12.01 \%$ and $10.80 \%$.
Visual acuity

$23.38 \%$ or 58 of the patients had a decrease in visual acuity (Figure 2).

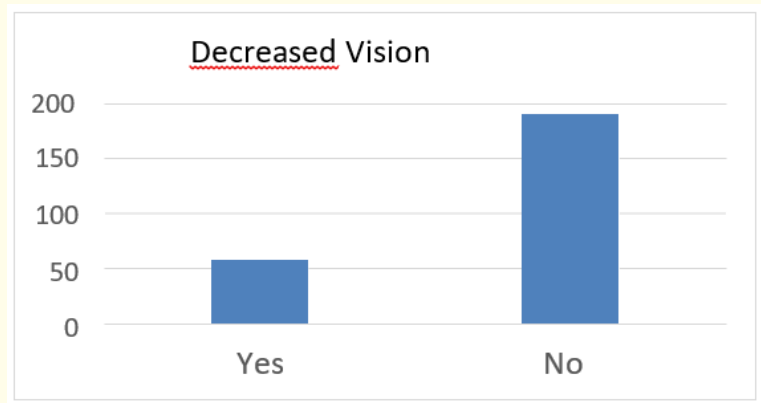

Figure 2: Graph representing visual acuity.

\section{Associated ophthalmological pathologies}

Table 5 summarizes the associated ophthalmological pathologies found in patients.

\begin{tabular}{|l|c|c|}
\hline & Size & Percentage \% \\
\hline Conjunctivitis-ametropia-glaucoma & 3 & 1.20 \\
\hline Conjunctivitis-ametropia & 20 & 8.06 \\
\hline conjunctivitis-glaucoma & 1 & 0.40 \\
\hline Conjunctivitis-cataract & 8 & 3.22 \\
\hline Total & 32 & 12.91 \\
\hline
\end{tabular}

Table 5: Associated ophthalmological pathologies.

In our study, the ophthalmological pathologies associated with conjunctivitis were the wearing of corrective glasses in $8.06 \%$ of cases, cataracts in $3.22 \%$ of cases. The association of conjunctivitis with ametropia and glaucoma in $1.20 \%$ of cases. Glaucoma was noted in our patients with conjunctivitis in $0.40 \%$ of cases.

\section{Discussion}

\section{Method}

Our work consisted of a descriptive cross-sectional retrospective study on the files of patients who consulted in the ophthalmology department of the CHU Kara over the period from January 1, 
2017 to December 31, 2019, i.e. a period of 03 years and aimed to assess the hospital prevalence of conjunctivitis over this period.

The same method was used by Wane., et al. [9], Vonor., et al. [10] in their study. Farissi., et al. [11] in Morocco on the prevalence of allergic conjunctivitis in asthma patients had also carried out a retrospective study as did Wade., et al. [12].

On the other hand, Sow., et al. [13] had performed a prospective study on viral conjunctivitis. As Koki., et al. [14] who had to carry out a single-center, documentary, cross-sectional and descriptive hospital study in the specialized ophthalmology service of the Yaoundé Hospital of Instruction and Application of the Armies on the profile of eye diseases in the military environment in Cameroon; Banla., et al. [15] had carried out a cross-sectional study on the prevalence and causes of the main eye diseases in schools in the central region of Togo.

\section{Hospital frequency of conjunctivitis}

We have listed a total of 550 files of patients who consulted in the ophthalmology department at CHU Kara during our study period. The diagnosis of conjunctivitis was retained in 248 patients, i.e. the hospital frequency of $45.09 \%$. Our results are close to Kassir in Lebanon [16], Kumah., et al. in Ghana [17] and Vonor., et al. in Togo (70), which respectively found a frequency of 39.9\%; 33.2\% and $52.7 \%$ On the other hand, our figures are higher than those obtained by Banla., et al. [15], Koki., et al. who found a frequency of $21.0 \%$ and $4 \%$ (66). This could be explained by their study population which was the school and military environment.

Age

The study of the age distribution in our study showed a predominance of the group of patients aged less than 40 years in 69\% of cases. The average age of our patients was 30.20 years with extremes of 6 months and 78 years. This corroborates that of SOW., et al. in Senegal [13] which had returned to 32 years with extremes of 9 months, and 75 years; that of Berny., et al. in Morocco where the average age was 35 years [19].

Our results differ from those found by Bobba., et al. in Australia and New Zealand with an average age of 74 years (range, 28-94 years) [20]. This could be explained by the old age of their population. Takou V., et al. in their study, the most affected age group was 0 to 9 years with $46 \%$ and the average age was 20.68 years with extremes of 7 days to 83 years. This difference could be explained by the fact that this was a randomized cross-sectional study that only looked at infectious conjunctivitis.

\section{Gender}

- The results of our study show respectively $61 \%$ of cases of conjunctivitis in women against 39\% of cases in men with an $\mathrm{M} / \mathrm{F}$ sex ratio of 0.65 . The results we obtained agree with the data from the studies by Farissi., et al. [11] which found a clear predominance of women (79\%).

- $\quad$ On the other hand, Vonor., et al. in Togo did not find a significant difference with a sex ratio M/ F of 1.01 (62) as well as Sow., et al. in Senegal [13], Malu., et al. in Nigeria [21].

- $\quad$ Our results differ from that of Güemes-Villahoz., et al. in Germany [22] who found male predominance with a sex ratio of 1.56. This could be explained by the study population with a minority of women.

\section{Profession}

- According to the data of our results, pupils/students and civil servants came in the foreground with respectively $34.80 \%$ and $22.30 \%$, followed by housewives (9.30\%). Manual workers and others accounted for $7.70 \%$ and $9.30 \%$.

- $\quad$ Our figures approximate those found by Sow., et al. in Senegal [13]. This could be explained by the promiscuity associated with these occupational groups.

- $\quad$ Farmers were the least affected in our study, at $2.00 \%$. That could be explained by the lack of health education.

\section{Symptoms}

- In our study, it was mainly eye pain (39.92\%) which was the major functional sign. The eye pain described by patients is generally discomfort and is said to be an abuse of language.

- Among others pruritus (37.01\%), visual blurring (23.39\%), redness (16.94\%) dominated the complaints of patients in our series. These results are comparable to those of Chenge., et al. [23] who classified pruritus as a major functional sign (86\%), followed by redness (51\%) and tearing (48\%).

\section{Visual acuity}

$23.38 \%$ of the patients had a decrease in visual acuity and of which $55.17 \%$ of these had an ophthalmologic pathology associ- 
ated with conjunctivitis. The occurrence of conjunctivitis in subjects wearing corrective lenses in $8.06 \%$ of cases and subjects with ametropia could explain the decrease in visual acuity observed in our study.

\section{Associated ophthalmological pathologies}

In our series, there were other eye conditions coexisting with conjunctivitis. We found the wearing of corrective lenses in 8.06\% of cases. This corroborates with Wade., et al. [12] who found in their study on allergic conjunctivitis at the Sheikh Zayed Regional Eye Care Center, The Gambia that refractive errors were found to be the most common at 7.4\%. Mimura., et al. [24] in their study found $22.1 \%$ and concluded that refractive error may be a risk factor for allergic conjunctivitis. Another coexisting condition was cataract in $3.22 \%$ of cases. Wade., et al. found $1.3 \%$ for cataracts. These can also be complications from long term steroid use.

\section{Conclusion}

Conjunctivitis is the most common eye condition and the most common cause of red eyes. It mainly affects the young population. Our study was descriptive cross-sectional retrospective on a random sampling of 550 files of patients who consulted in the ophthalmology department of CHU Kara over the period from January 1, 2017 to December 31, 2019 and whose diagnosis of conjunctivitis was retained, i.e. 248 The major difficulty lay in the incomplete nature of certain data in the files. The mean age was 30.20 years and the female sex was predominant (61\%). The pupils and students group (34.90\%) and civil servants $(22.30 \%)$ were the most affected. Eye pain and pruritus were the most frequent reason for consultation, i.e. $39.92 \%$ and $37.51 \%$. The hospital frequency of conjunctivitis was $45.09 \%$ at CHU Kara. Community measures should therefore be taken to minimize the impact on societies, especially schools and universities.

\section{Bibliography}

1. Dictionnaire Larousse de la langue française Online.

2. Morrow GL and Abbott RL. "Conjunctivitis". American Family Physician57.4 (1998): 735-746.

3. Llotet S and Mokin Y. "Guide pratique des examens de laboratoire en ophtalmologie”. Ed. Masson. 65 (1988): 84-92.

4. Alfonso SA., et al. "Conjunctivitis: Primary Care”. Clinics in Office Practice 42 (2015): 325- 45.
5. Reinhards J., et al. "Studies in the epidemiology and control of seasonal conjunctivitis and trachoma in southern Morocco". Bulletin of the World Health Organization 39 (1968): 497-445.

6. Cahuzac G., et al. "Les conjonctivites tropicales". Médecine d'Afrique Noire 4 (1984): 217-222.

7. Castan R. "Conjonctivites tropicales: étiologies et validation des caractères Cliniques". Revue Internationale Du Trachome 68 (1991): 63-73.

8. Amy H Buchanan. Family Medicine 51.1 (219): 58-58.

9. Wane AM., et al. "Conjonctivite allergique du nourrisson : à propos de 130 cas colligés à l'hôpital pour enfants de DIAMNIADIO". Journal Français D'Ophtalmologie 7 (2018): 58-56.

10. Kokou V., et al. "Les conjonctivites néonatales dans le canton de Glidji au Sud du Togo: une étude transversale à propos de 159 nouveau-nés". Pan African Medical Journal (2016): 24.

11. Farissi C., et al. "Prévalence de la conjonctivite allergique chez les patients asthmatiques". Revue des Maladies Respiratoires Actualités 13 (2021): 69-70.

12. Wade PD., et al. "Allergic Conjunctivitis at Sheikh Zayed Regional Eye Care Center, Gambia". Journal of Ophthalmic and Vision Research 7 (2012): 24-28.

13. Sow AS., et al. "Expérience sénégalaise des conjonctivites virales aiguës". Journal Français D'Ophtalmologie 2017; 40 (2017): 297-202.

14. Koki G., et al. "Profil des affections oculaires en milieu militaire au Cameroun”. Journal Français D’Ophtalmologie 7 (2015): 8987.

15. Banla M., et al. "Prévalence et causes des principales affections oculaires en milieu scolaire dans la région centrale du Togo". Journal Français D’Ophtalmologie 31 (2008): 20-29.

16. Kassir MS. "La pathologie ophtalmologique de dispensaire au Liban : l'exemple de Saïda”. Cahiers d'études et de recherches francophones/Santé 10 (2000): 237-242.

17. Kumah DB., et al. "Prevalence of allergic conjunctivitis among basic school children in the Kumasi Metropolis (Ghana): a community-based cross-sectional study". BMC Ophthalmology 15 (2015): 69-65.

18. Vonor K., et al. "Profil des affections oculaires de l'enfant en pratique ophtalmologique au CHU-Tokoin de Lomé (Togo)". Médecine d'Afrique Noire 61.7 (2014).

Citation: Kokou Messan Amedome., et al. "Prevalence of Conjunctivitis in Low Developing Countries: The Case in University Teaching Hospital of Kara in Togo". Acta Scientific Ophthalmology 5.1 (2022): 21-26. 
19. Berny L., et al. "Prévalence de la conjonctivite chez les patients asthmatiques". Revue Française d'Allergologie 57 (2017): 263265.

20. Bobba S., et al. "Incidence, clinical features and diagnosis of cicatrising conjunctivitis in Australia and New Zealand". Eye (Lond) 32 (2018): 1636-1643.

21. Malu KN. "Allergic conjunctivitis in Jos-Nigeria". Nigerian Medical Journal 55 (2014): 166-170.

22. Güemes-Villahoz N., et al. "Conjunctivitis in COVID-19 patients: frequency and clinical presentation". Graefe's Archive for Clinical and Experimental Ophthalmology 258 (2020): 2501-2507.

23. Chenge B and Makumyamviri AM. "La limbo-conjonctivite endémique des tropiques à Lubumbashi république du Congo". Bulletin de la Societe belge d'ophtalmologie 390 (2003): 9-16.

24. Mimura T., et al. "Relation entre réfraction et conjonctivite allergique". Eye (Londres) 23 (2009): 63-66.

\section{Assets from publication with us}

- Prompt Acknowledgement after receiving the article

- Thorough Double blinded peer review

- Rapid Publication

- Issue of Publication Certificate

- High visibility of your Published work

Website: www.actascientific.com/

Submit Article: www.actascientific.com/submission.php

Email us: editor@actascientific.com

Contact us: +919182824667

Citation: Kokou Messan Amedome., et al. "Prevalence of Conjunctivitis in Low Developing Countries: The Case in University Teaching Hospital of Kara in Togo". Acta Scientific Ophthalmology 5.1 (2022): 21-26. 